\title{
Spatial separation of pyrrole and pyrrole-water clusters
}

\author{
Melby Johny ${ }^{\mathrm{a}, \mathrm{b}}$, Jolijn Onvlee $^{\mathrm{a}}$, Thomas Kierspel ${ }^{\mathrm{a}, \mathrm{b}, \mathrm{c}, 1}$, Helen Bieker $^{\mathrm{a}, \mathrm{b}, \mathrm{c}}$, Sebastian Trippel ${ }^{\mathrm{a}, \mathrm{c}, *}$, \\ Jochen Küpper ${ }^{\mathrm{a}, \mathrm{b}, \mathrm{c}}$ \\ ${ }^{a}$ Center for Free-Electron Laser Science, Deutsches Elektronen-Synchrotron DESY, Notkestrasse 85, 22607 Hamburg, Germany \\ ${ }^{b}$ Department of Physics, Universität Hamburg, Luruper Chaussee 149, 22761 Hamburg, Germany \\ ${ }^{c}$ The Hamburg Center for Ultrafast Imaging, Universität Hamburg, Luruper Chaussee 149, 22761 Hamburg, Germany
}

\begin{abstract}
We demonstrate the spatial separation of pyrrole and pyrrole $\left(\mathrm{H}_{2} \mathrm{O}\right)$ clusters from the other atomic and molecular species in a supersonically-expanded beam of pyrrole and traces of water seeded in high-pressure helium gas. The experimental results are quantitatively supported by simulations. The obtained pyrrole $\left(\mathrm{H}_{2} \mathrm{O}\right)$ cluster beam has a purity of $\sim 100 \%$. The extracted rotational temperature of pyrrole and pyrrole $\left(\mathrm{H}_{2} \mathrm{O}\right)$ from the original supersonic expansion is $T_{\text {rot }}=0.8 \pm 0.2 \mathrm{~K}$, whereas the temperature of the deflected, pure-pyrrole $\left(\mathrm{H}_{2} \mathrm{O}\right)$ part of the molecular beam corresponds to $T_{\text {rot }} \approx 0.4 \mathrm{~K}$.
\end{abstract}

Keywords: pyrrole, pyrrole $\left(\mathrm{H}_{2} \mathrm{O}\right)$ cluster, Stark effect, cold molecules, electric deflection, species separation

\section{Introduction}

Studies of solvation effects of biologically relevant aromatic molecules provide details on the influence of the molecule's local environment on its function and on the nature of molecular interactions, as well as insights into the functions of complex biological systems [1]. Prototypical model chromophores such as imidazole and pyrrole were used to build synthetic polyamide ligands for the recognition of the Watson-Crick base pairs in the DNA minor groove [2]. Furthermore, pyrrole is a model of tryptophan's indole chromophore, one of the strongest near-UV absorbers in proteins. Similarly, pyrrole is responsible for the photoconversion mechanism in the phytochrome enzyme [3] and it is a promising building block for organic dye-sensitized solar cells [4] as well as biological sensors [5].

A key reason for the intriguing photophysics of the above-mentioned chromophores is the excited ${ }^{1} \pi \sigma^{*}$ state, which is repulsive along the N-H-stretching

\footnotetext{
* Corresponding author

Email address: sebastian.trippel@cfel.de (Sebastian Trippel)$$
U R L \text { : }
$$

https://www.controlled-molecule-imaging.org/ (Sebastian Trippel)

${ }^{1}$ Current address: Department of Chemistry, University of Basel, Klingelbergstrasse 80, Basel 4056, Switzerland

Preprint submitted to Chemical Physics Letters
}

coordinate [6-8]. The photophysics and photochemistry of these molecules is fairly sensitive to the environment [9]. In a bottom-up approach, spectroscopic and theoretical investigations were performed for micro-solvated clusters to get fundamental insights into their photophysical and photochemical properties $[7,10,11]$. Recently performed experiments have provided evidence for ultrafast intermolecular relaxation processes in electronicallyexcited microsolvated tetrahydrofuran-water [12] and indole-water [13] clusters. This reflects one of the proposed efficient mechanisms for radiation damage processes of biomolecules via auto-ionization caused by secondary electrons [14]. Time-resolved experiments, such as photoion and photoelectron spectroscopy, aiming at the investigation of the photophysics and photochemistry of pyrrole, were performed to study the dynamics of $\mathrm{H}$ elimination from the N-H site of the molecule mediated by the excitation of the ${ }^{1} \pi \sigma^{*}$ state $[7,15-17]$.

For pyrrole $\left(\mathrm{H}_{2} \mathrm{O}\right)$ clusters theoretical calculations predict that an electron is transferred across the hydrogen bond without photodissociation of the pyrrole moiety $[8,9]$. Hence, detailed investigations of the photophysics of pyrrole $\left(\mathrm{H}_{2} \mathrm{O}\right)$, and their comparison with the existing observations for indole $\left(\mathrm{H}_{2} \mathrm{O}\right)[7,11]$, promises to unravel these fundamental processes in the intermolecular interactions 
as well as the radiation damage of biological systems.

Advanced experiments aiming at unraveling these ultrafast dynamics often rely on pure samples of the individual species. Such controlled samples were previously exploited in investigations of the photophysics of indole [18] and indole $\left(\mathrm{H}_{2} \mathrm{O}\right)$ clusters [13] following site-specific soft $\mathrm{x}$-ray ionization and are even amenable to coherent-x-ray-diffraction studies [19]. These experiments relied on the spatial separation of individual species by the electrostatic deflector [20], which was previously demonstrated for the separation of indole $\left(\mathrm{H}_{2} \mathrm{O}\right)$ from indole [20 $22]$.

Here, we demonstrate the spatial separation of pyrrole, a sub unit of indole and tryptophan, and the microsolvated pyrrole $\left(\mathrm{H}_{2} \mathrm{O}\right)$ cluster. The structure of pyrrole and pyrrole $\left(\mathrm{H}_{2} \mathrm{O}\right)$ was studied using microwave spectroscopy $[23,24]$ and it was concluded that the singly-hydrogen-bonded pyrrole $\left(\mathrm{H}_{2} \mathrm{O}\right)$ cluster has a well defined structure, with the water attached to the $\mathrm{N}-\mathrm{H}$ site of pyrrole [8, 23].

\section{Experimental setup}

A schematic representation of the experimental setup is shown in Figure 1. An Even-Lavie valve [25] was used to generate a pulsed molecular beam by supersonic expansion of a few millibar of pyrrole (Sigma Aldrich, $>98 \%$ ) and traces of water seeded in $\sim 80$ bar of helium into vacuum. The valve was operated at a repetition rate of $250 \mathrm{~Hz}$ and was heated to $65^{\circ} \mathrm{C}$. The expanded molecular beam was then skimmed twice using conical skimmers (Beam Dynamics, model 50.8, $\varnothing=3.0 \mathrm{~mm} \&$ model 40.5, $\varnothing=1.5 \mathrm{~mm}$ ), which were placed at distances of $6.5 \mathrm{~cm}$ and $30.2 \mathrm{~cm}$ downstream the nozzle, respectively. An inhomogeneous electric field created by the so-called $b$-type deflector [26] was used to disperse the molecular beam according to the species' effective-dipole-moment-to-mass ratio [20, 27, 28]. The molecular beam was cut by a vertically adjustable knife edge placed $1.5 \mathrm{~cm}$ downstream of the exit of the deflector, which allowed for an improved separation of all species present in the molecular beam [22]. The experiments were conducted by placing the knife edge at a height where it cut off the undeflected ( $0 \mathrm{kV}$ applied on deflector electrodes) molecular beam at the center of the vertical column density profile. The molecular beam was further skimmed by a conical skimmer (Beam Dynamics, model 50.8 with $\varnothing=1.5 \mathrm{~mm}$ ) placed $4 \mathrm{~cm}$ downstream of the exit of the deflector. The transverse positions of the valve, skimmers, and the deflector were adjustable using motorized translation stages. A laser pulse with a duration of $\sim 30 \mathrm{fs}$, a wavelength centered at $800 \mathrm{~nm}$, focused to $\varnothing \approx 50 \mu \mathrm{m}$, and directed perpendicular to the molecular beam ionized molecules in the extraction region of a time-of-flight mass-spectrometer (TOF-MS) placed $17.6 \mathrm{~cm}$ downstream of the last skimmer. The peak intensity of the laser pulse was $\sim 2 \times 10^{14} \mathrm{~W} / \mathrm{cm}^{2}$. The ions generated due to the strong-field ionization were detected using a micro-channel plate $(\mathrm{MCP})$, operated in single-shot readout.

\section{Results and discussions}

Figure 1 a shows the structure, rotational constants [23, 24], permanent dipole moment [23, 24], and the Stark energies of pyrrole (red curves) and pyrrole $\left(\mathrm{H}_{2} \mathrm{O}\right)$ (blue curves) for the $J=0,1$ rotational states. The Stark energies were calculated using CMIsTARK [29] within the rigid-rotor approximation, as justified by previous experimental and theoretical work on the indole $\left(\mathrm{H}_{2} \mathrm{O}\right)$ cluster $[21,30]$. Pyrrole has a 64 \% smaller Stark-energy shift than pyrrole $\left(\mathrm{H}_{2} \mathrm{O}\right)$ for the $J=0$ rotational state at an electric field strength of $E \approx 200 \mathrm{kV} / \mathrm{cm}$. This enabled full spatial separation of pyrrole $\left(\mathrm{H}_{2} \mathrm{O}\right)$ from pyrrole in a cold molecular beam using the electrostatic deflector.

The molecular beam species underwent fragmentation following the strong-field-ionization process. Hence contributions of ionic fragments from larger clusters in specific mass gates were observed in our spectra. A $\sim 28 \%$ probability of pyrrole $\left(\mathrm{H}_{2} \mathrm{O}\right)^{+}$fragmenting into pyrrole ${ }^{+}$was experimentally obtained for our specific laser pulse properties. A detailed description of the fragmentation ratios and utilized mass gates for the specific ion signals is presented in the Supplementary Information. The fragmentation corrected vertical column density profile for undeflected pyrrole is shown as black dots in Figure 2 a. The undeflected profiles of pyrrole $\left(\mathrm{H}_{2} \mathrm{O}\right)$ and other species in the TOF-MS spectra had similar shapes and are not shown. In addition, the fragmentation corrected deflection profiles of both, pyrrole (red dots) and pyrrole $\left(\mathrm{H}_{2} \mathrm{O}\right)$ (blue dots), are shown for voltages of $\pm 7 \mathrm{kV}$ applied across the deflector. All quantum states are strong-field seeking at the relevant electric field strengths experienced by the investigated molecules and clusters inside the deflector. Therefore, all species are deflected downward, in 


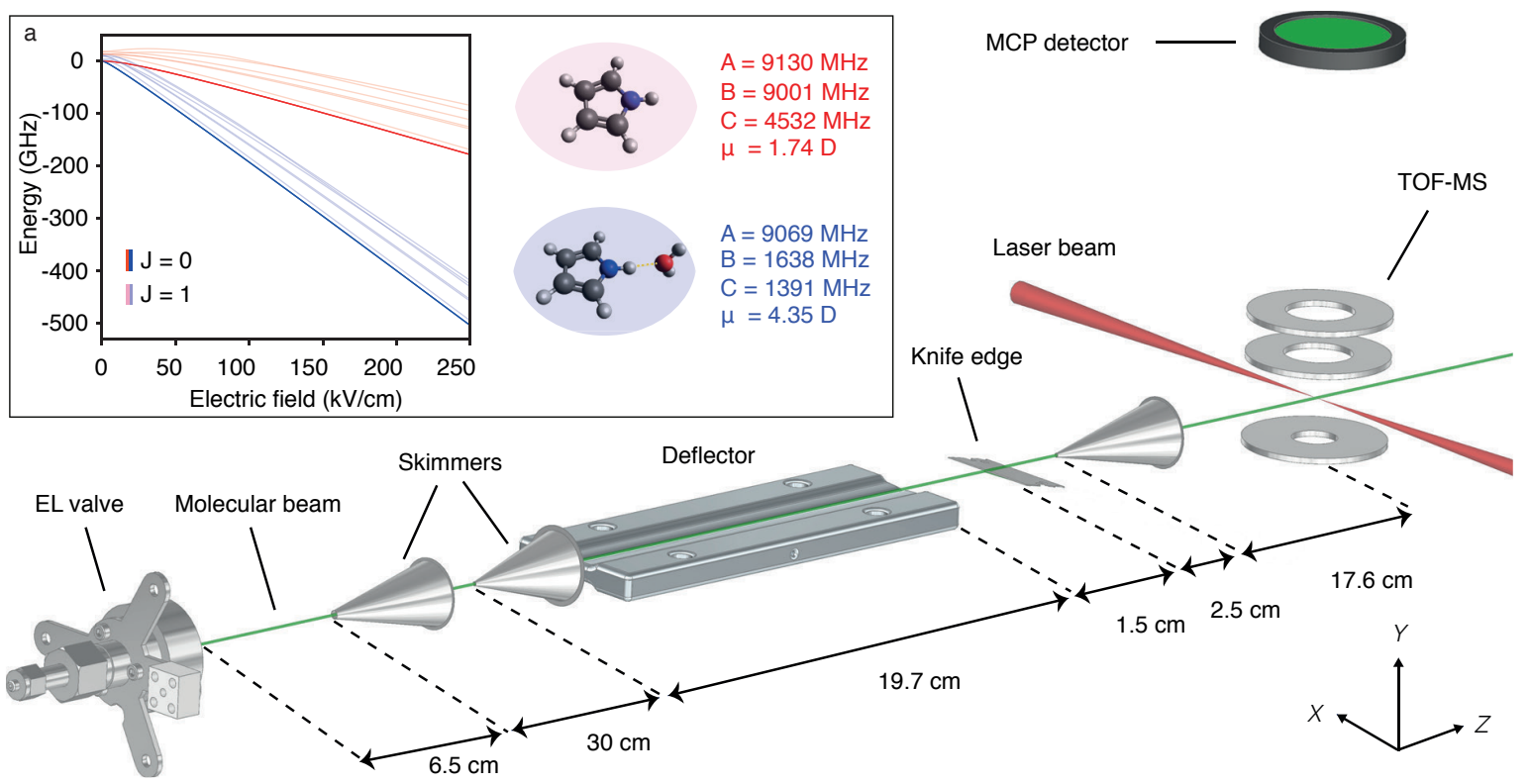

Figure 1: Schematic representation of the experimental setup and the definition of the coordinate system. (a) Stark energies and molecular constants of pyrrole (red) and pyrrole $\left(\mathrm{H}_{2} \mathrm{O}\right)$ (blue).

the negative $Y$ direction [26]. The experimental deflection profiles of pyrrole $\left(\mathrm{H}_{2} \mathrm{O}\right)$ shows the strongest deflection, down to $Y=-1.8 \mathrm{~mm}$, whereas pyrrole was only deflected down to $Y=-1.2 \mathrm{~mm}$. Significant deflection of $\mathrm{H}_{2} \mathrm{O}$ is not expected due to its small effective dipole moment [31]. The deflection profiles of larger cluster species, i. e., pyrrole $\left(\mathrm{H}_{2} \mathrm{O}\right)_{2}$ and (pyrrole) $)_{2}$, are shown and discussed in the Supplementary Information.

The solid lines in Figure 2 a are simulated profiles obtained from the results of Monte-Carlo trajectory calculations that took into account the geometrical constraints of the mechanical apertures in the experimental setup [27]. These simulated deflection profiles of pyrrole and pyrrole $\left(\mathrm{H}_{2} \mathrm{O}\right)$ matched the experimental data assuming an initial rotational temperature of the molecular beam entering the deflector of $T_{\text {rot }}=0.8 \pm 0.2 \mathrm{~K}$. In the deflected part of the beam at $Y=-1.6 \mathrm{~mm}$ the relative populations of the rotational states of pyrrole $\left(\mathrm{H}_{2} \mathrm{O}\right)$ were determined from the simulations. Although this rotational-state distribution is non-thermal, it approximately corresponds to a thermal distribution of $0.4 \mathrm{~K}$, see Supplementary Information. This indicates that an ensemble of very cold molecules is generated using the deflector $[32,33]$ and that ultracold ensembles, even of isolated well-defined molecular clusters, can be generated in the most deflected part of a dispersed molecular beam.

The purity of pyrrole $\left(\mathrm{H}_{2} \mathrm{O}\right)$ (pyrrole), as defined by the ratio of the pyrrole $\left(\mathrm{H}_{2} \mathrm{O}\right)$ (pyrrole) signal to the sum of signals of all other species observed is shown in Figure $2 \mathrm{~b}$, see Supplementary Information for details of the analysis. This demonstrates that a molecular beam of pyrrole $\left(\mathrm{H}_{2} \mathrm{O}\right)$ with a purity of $\sim 100 \%$ was produced at vertical positions $-1.8 \mathrm{~mm}<Y<-1.3 \mathrm{~mm}$. The column density profile of helium is not shown here, but is expected to be only slightly broader than the undeflected $(0 \mathrm{kV})$ profile of the molecular species, owing to its lighter mass. Furthermore, helium is expected to be only marginally deflected by a few $\mu \mathrm{m}$ due to its small polarizability [26]. Hence, the extracted pure molecular beam of pyrrole $\left(\mathrm{H}_{2} \mathrm{O}\right)$ should also be free from helium gas at $Y=-1.6 \mathrm{~mm}$.

\section{Conclusion}

We demonstrated the spatial separation of the pyrrole $\left(\mathrm{H}_{2} \mathrm{O}\right)$ cluster in a molecular beam, i. e., from pyrrole, water, larger clusters, and the seed gas. A purity of $\sim 100 \%$ of pyrrole $\left(\mathrm{H}_{2} \mathrm{O}\right)$ was obtained in the most deflected part of the molecular beam. Simulated deflection profiles were in excellent agreement with the experiment. They yielded a rotational 

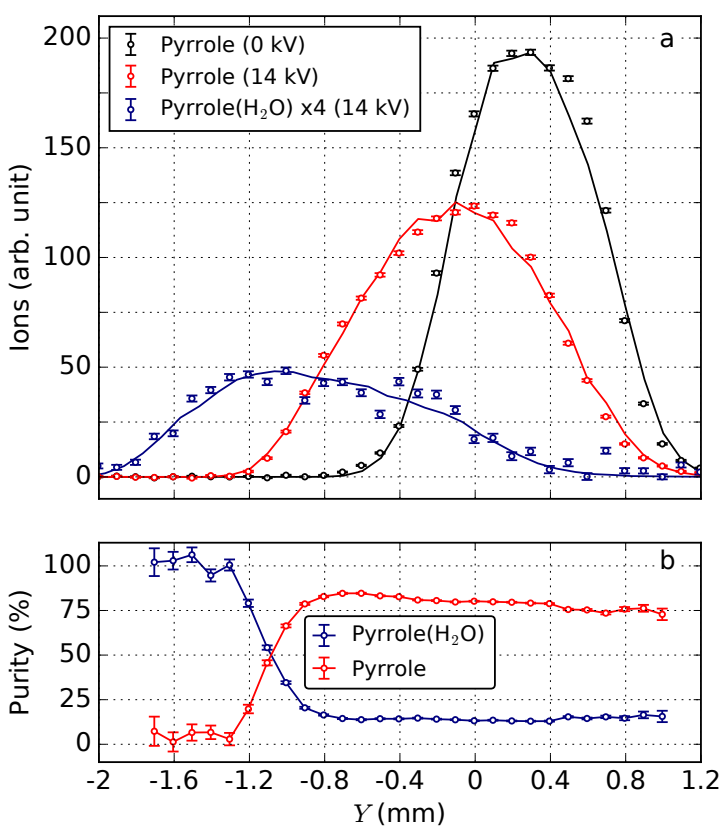

Figure 2: a) Measured vertical column density profiles for the undeflected $(0 \mathrm{kV})$ pyrrole (black dots), deflected $(14 \mathrm{kV})$ pyrrole (red dots) and pyrrole $\left(\mathrm{H}_{2} \mathrm{O}\right)$ (blue dots). Solid lines are the corresponding simulated profiles. b) Purity of pyrrole (red) and pyrrole $\left(\mathrm{H}_{2} \mathrm{O}\right)$ (blue).

temperature of $T_{\text {rot }}=0.8 \pm 0.2 \mathrm{~K}$, for pyrrole and pyrrole $\left(\mathrm{H}_{2} \mathrm{O}\right)$, in the initial molecular beam and of $T_{\text {rot }} \approx 0.4 \mathrm{~K}$ in the deflected pure pyrrole $\left(\mathrm{H}_{2} \mathrm{O}\right)$ beam.

These pure beams of pyrrole $\left(\mathrm{H}_{2} \mathrm{O}\right)$ provide a crucial ingredient for photophysics studies aiming at time-resolved hydrogen bond formation/dissociation dynamics, e.g., in ultrafast laser pump and x-ray probe experiments. Further interesting aspects will be the control of the orientation in the laboratory frame by laser aligning or mixed-field orienting pyrrole $\left(\mathrm{H}_{2} \mathrm{O}\right)$ clusters $[30,32,34]$. The separated pure species are also ideally suited for experiments to image the structure and dynamics of the complex in the molecular frame, e.g., via molecular-frame photoelectron angular distributions (MFPADs), gas phase x-ray diffraction, or laser induced electron diffraction(LIED) experiments [19, 35-38].

\section{Acknowledgments}

This work has been supported by the European Union's Horizon 2020 research and innovation program under the Marie Skłodowska-Curie Grant
Agreement 641789 "Molecular Electron Dynamics investigated by Intense Fields and Attosecond Pulses" (MEDEA), the excellence cluster "The Hamburg Center for Ultrafast Imaging - Structure, Dynamics and Control of Matter at the Atomic Scale" (CUI, DFG-EXC1074), the European Research Council under the European Union's Seventh Framework Program (FP7/2007-2013) through the Consolidator Grant COMOTION (ERC-Küpper-614507), and by the Helmholtz Association through the Virtual Institute 419 "Dynamic Pathways in Multidimensional Landscapes" and the "Initiative and Networking Fund". J.O. gratefully acknowledges a fellowship by the Alexander von Humboldt Foundation.

\section{References}

\section{References}

[1] M. F. Colombo, D. C. Rau, V. A. Parsegian, Protein Solvation in Allosteric regulation: A Water Effect on Hemoglobin, Science 256 (5057) (1992) 655-659. doi:10.1126/science. 1585178

URL http://science.sciencemag.org/content/256/ $5057 / 655$

[2] S. White, J. W. Szewczyk, J. M. Turner, E. E. Baird, P. B. Dervan, Recognition of the four Watson-Crick base pairs in the DNA minor groove by synthetic ligands, Nature 391 (1998) 468-471. doi:10.1038/35106. URL http://dx.doi.org/10.1038/35106

[3] A. T. Ulijasz, G. Cornilescu, C. C. Cornilescu, J. Zhang, M. Rivera, J. L. Markley, R. D. Vierstra, Structural basis for the photoconversion of a phytochrome to the activated Pfr form, Nature 463 (2010) 250-254. doi: 10.1038/nature08671.

URL https://www . nature.com/articles/nature08671

[4] Y.-S. Yen, Y.-C. Hsu, J. T. Lin, C.-W. Chang, C.-P. Hsu, D.-J. Yin, Pyrrole-based organic dyes for dye-sensitized solar cells, J. Phys. Chem. C 112 (32) (2008) $12557-$ 12567. doi: $10.1021 / \mathrm{jp} 801036 \mathrm{~s}$. URL https://doi.org/10.1021/jp801036s

[5] F. Tan, L. Cong, X. Li, Q. Zhao, H. Zhao, X. Quan, J. Chen, An electrochemical sensor based on molecularly imprinted polypyrrole/graphene quantum dots composite for detection of bisphenol $\mathrm{A}$ in water samples, Sens. Actuator B Chem. 233 (2016) 599-606. doi:10.1016/j.snb.2016.04.146.

URL http://linkinghub.elsevier.com/retrieve/ pii/S0925400516306281

[6] A. L. Sobolewski, W. Domcke, C. Dedonder-Lardeux, C. Jouvet, Excited-state hydrogen detachment and hydrogen transfer driven by repulsive ${ }^{1} \pi \sigma^{*}$ states: A new paradigm for nonradiative decay in aromatic biomolecules, Phys. Chem. Chem. Phys. 4 (2002) 10931100. doi:10.1039/B110941N.

URL http://dx.doi.org/10.1039/B110941N

[7] H. Lippert, H.-H. Ritze, I. V. Hertel, W. W Radloff, Femtosecond time-resolved hydrogen-atom elimination from photoexcited pyrrole molecules, Chem. Phys. Lett. 5 (2004) 1423-1427. doi:10.1002/cphc.200400079. URL https://doi.org/10.1002/cphc. 200400079 
[8] I. Frank, K. Damianos, Excited state dynamics in pyrrole-water clusters: First principles simulation, Chem. Phys. 343 (2008) 347-352. doi:10.1016/j.chemphys. 2007.08.029.

URL https://doi.org/10.1016/j.chemphys.2007.08. 029

[9] A. L. Sobolewski, W. Domcke, Photoejection of electrons from pyrrole into an aqueous environment: ab initio results on pyrrole-water clusters, Chem. Phys. Lett. 321 (5-6) (2000) 479-484. doi: 10.1016/S0009-2614(00) 00404-8.

URL http://linkinghub.elsevier.com/retrieve/ $\mathrm{pii} / \mathrm{S} 0009261400004048$

[10] H. Lippert, V. Stert, L. Hesse, C. P. Schulz, I. V. Hertel, W. Radloff, Ultrafast photoinduced processes in indole-water clusters, Chem. Phys. Lett. 376 (1-2) (2003) 40-48. doi:10.1016/S0009-2614(03) 00921-7. URL http://linkinghub.elsevier.com/retrieve/ pii/S0009261403009217

[11] A. L. Sobolewski, W. Domcke, Photoinduced charge separation in indole-water clusters, Chem. Phys. Lett. 329 (1-2) (2000) 130-137. doi: 10.1016/S0009-2614(00) 00983-0.

URL http://linkinghub.elsevier.com/retrieve/ pii/S0009261400009830

[12] X. Ren, E. Wang, A. D. Skitnevskaya, A. B. Trofimov, G. Kirill, A. Dorn, Experimental evidence for ultrafast intermolecular relaxation processes in hydrated biomolecules, Nat. Phys. 79 (2018) 1745. doi:10.1038/ s41567-018-0214-9.

URL https://doi.org/10.1038/s41567-018-0214-9

[13] T. Kierspel, Imaging structure and dynamics using controlled molecules, Dissertation, Universität Hamburg, Hamburg, Germany (2016). doi:10.3204/ PUBDB-2017-02127.

[14] E. Alizadeh, T. M. Orlando, L. Sanche, Biomolecular damage induced by ionizing radiation: The direct and indirect effects of low-energy electrons on DNA, Annu. Rev. Phys. Chem. 66 (2015) 379-398. doi:10.1146/annurev-physchem-040513-103605.

URL https://www. annualreviews.org/doi/pdf/10. 1146/annurev-physchem-040513-103605

[15] M. Ashfold, B. Cronin, A. L. Devine, R. Dixon, M. G. D. $\mathrm{Nix}$, The role of $\pi \sigma^{*}$ excited states in the photodissociation of heteroaromatic molecules, Science 312 (2006) 1637-1640. doi:10.1126/science.1125436.

URL http://science.sciencemag.org/content/312/ $5780 / 1637 /$ tab-pdf

[16] G. M. Roberts, C. A. Williams, H. Yu, A. S. Chatterley, J. D. Young, S. Ullrich, V. G. Stavros, Probing ultrafast dynamics in photoexcited pyrrole: timescales for ${ }^{1} \pi \sigma^{*}$ mediated H-atom elimination, Faraday Disc. 163 (2013) 95-115. doi:10.1039/c2fd20140b.

URL http://pubs.rsc.org/en/content/articlepdf/ 2013/fd/c2fd20140b

[17] O. M. Kirkby, M. A. Parkes, S. P. Neville, G. A Worth, H. H. Fielding, Non-radiative relaxation dynamics of pyrrole following excitation in the range 249.5-200 nm, Chem. Phys. Lett. 683 (2017) 179-185. doi: $10.1016 / \mathrm{j}$. cplett.2017.04.035.

URL https://doi.org/10.1016/j.cplett.2017.04. 035

[18] T. Kierspel, C. Bomme, M. Di Fraia, J. Wiese, D. Anielski, S. Bari, R. Boll, B. Erk, J. S. Kienitz, N. L. M. Müller, D. Rolles, J. Viefhaus, S. Trippel, J. Küpper,
Photophysics of indole upon x-ray absorption, Phys. Chem. Chem. Phys. 20 (2018) 20205. arXiv: 1802.02964, doi: $10.1039 / \mathrm{C} 8 \mathrm{CP} 00936 \mathrm{H}$

URL https://dx.doi.org/10.1039/C8CP00936H

[19] J. Küpper, S. Stern, L. Holmegaard, F. Filsinger, A. Rouzée, A. Rudenko, P. Johnsson, A. V. Martin M. Adolph, A. Aquila, S. Bajt, A. Barty, C. Bostedt, J. Bozek, C. Caleman, R. Coffee, N. Coppola, T. Delmas, S. Epp, B. Erk, L. Foucar, T. Gorkhover, L. Gumprecht, A. Hartmann, R. Hartmann, G. Hauser, P. Holl, A. Hömke, N. Kimmel, F. Krasniqi, K.-U. Kühnel, J. Maurer, M. Messerschmidt, R. Moshammer, C. Reich, B. Rudek, R. Santra, I. Schlichting, C. Schmidt, S. Schorb, J. Schulz, H. Soltau, J. C. H. Spence, D. Starodub, L. Strüder, J. Thøgersen, M. J. J. Vrakking, G. Weidenspointner, T. A. White, C. Wunderer, G. Meijer, J. Ullrich, H. Stapelfeldt, D. Rolles, H. N. Chapman, X-ray diffraction from isolated and strongly aligned gas-phase molecules with a free-electron laser, Phys. Rev. Lett. 112 (2014) 083002. arXiv:1307.4577, doi: 10.1103/PhysRevLett.112.083002.

URL https://dx.doi.org/10.1103/PhysRevLett.112. 083002

[20] Y.-P. Chang, D. A. Horke, S. Trippel, J. Küpper, Spatially-controlled complex molecules and their applications, Int. Rev. Phys. Chem. 34 (2015) 557-590. arXiv: 1505.05632, doi:10.1080/0144235X.2015.1077838. URL http://dx.doi.org/10.1080/0144235X.2015. 1077838

[21] S. Trippel, Y.-P. Chang, S. Stern, T. Mullins, L. Holmegaard, J. Küpper, Spatial separation of state- and size-selected neutral clusters, Phys. Rev. A 86 (2012) 033202. arXiv:1208.4935, doi: 10.1103/PhysRevA.86.033202.

URL http://pra.aps.org/abstract/PRA/v86/i3/ e033202

[22] S. Trippel, M. Johny, T. Kierspel, J. Onvlee, H. Bieker, H. Ye, T. Mullins, L. Gumprecht, K. Długołęcki, J. Küpper, Knife edge skimming for improved separation of molecular species by the deflector, Rev. Sci. Instrum. 89 (2018) 096110. arXiv:1802.04053, doi:10.1063/1. 5026145.

URL https://doi.org/10.1063/1.5026145

[23] M. J. Tubergen, A. M. Andrews, R. L. Kuczkowski, Microwave spectrum and structure of a hydrogen-bonded pyrrole-water complex, J. Phys. Chem. 97 (29) (1993) 7451-7457. doi:10.1021/j100131a011. URL https://doi.org/10.1021/j100131a011

[24] U. Nygaard, J. Nielsen, J. Kirchheiner, G. Maltesen, C. S, J. Rastrup-Andersen, G. Sørensen, Microwave spectra of isotopic pyrroles: Molecular structure, dipole moment and ${ }^{14} \mathrm{~N}$ quadrupole coupling constants of pyrrole, J. Mol. Struct. 3 (6) (1969) 491-506. doi:10.1016/0022-2860 (69)80031-1.

URL https://doi.org/10.1016/0022-2860(69) 80031-1

[25] U. Even, J. Jortner, D. Noy, N. Lavie, N. Cossart-Magos, Cooling of large molecules below $1 \mathrm{~K}$ and He clusters formation, J. Chem. Phys. 112 (2000) 8068-8071. doi: 10.1063/1.481405. URL http://dx.doi.org/10.1063/1.481405

[26] J. S. Kienitz, K. Długołęcki, S. Trippel, J. Küpper, Improved spatial separation of neutral molecules, J. Chem. Phys. 147 (2) (2017) 024304. arXiv:1704.08912, doi: $10.1063 / 1.4991479$. 
URL https://doi.org/10.1063/1.4991479

[27] F. Filsinger, J. Küpper, G. Meijer, L. Holmegaard, J. H. Nielsen, I. Nevo, J. L. Hansen, H. Stapelfeldt, Quantum-state selection, alignment, and orientation of large molecules using static electric and laser fields, J. Chem. Phys. 131 (2009) 064309. arXiv:0903.5413, doi: $10.1063 / 1.3194287$.

URL http://scitation.aip.org/content/aip/ journal/jcp/131/6/10.1063/1.3194287

[28] F. Filsinger, U. Erlekam, G. von Helden, J. Küpper G. Meijer, Selector for structural isomers of neutral molecules, Phys. Rev. Lett. 100 (2008) 133003. arXiv: 0802.2795, doi:10.1103/PhysRevLett.100.133003.

URL http://dx.doi.org/10.1103/PhysRevLett.100. 133003

[29] Y.-P. Chang, F. Filsinger, B. Sartakov, J. Küpper, CMIstark: Python package for the stark-effect calculation and symmetry classification of linear, symmetric and asymmetric top wavefunctions in dc electric fields, Comp. Phys. Comm. 185 (2014) 339-349. arXiv:1308.4076, doi:10.1016/j.cpc.2013.09.001.

URL http://www.sciencedirect.com/science/ article/pii/S0010465513003019

[30] L. V. Thesing, A. Yachmenev, R. González-Férez, J. Küpper, Analyzing laser-induced alignment of weakly-bound molecular aggregates, Phys. Rev. A 98 (2018) 053412. arXiv:1808.01206, doi:10.1103/PhysRevA.98.053412.

URL https://journals.aps.org/pra/abstract/10. 1103/PhysRevA.98.053412

[31] D. A. Horke, Y.-P. Chang, K. Długołęcki, J. Küpper, Separating para and ortho water, Angew. Chem. Int. Ed. 53 (2014) 11965-11968. arXiv:1407.2056, doi:10 1002/anie. 201405986.

URL http://onlinelibrary.wiley.com/doi/10.1002/ anie.201405986/abstract

[32] L. Holmegaard, J. H. Nielsen, I. Nevo, H. Stapelfeldt, F. Filsinger, J. Küpper, G. Meijer, Laser-induced alignment and orientation of quantum-state-selected large molecules, Phys. Rev. Lett. 102 (2009) 023001. arXiv: 0810.2307, doi:10.1103/PhysRevLett.102.023001.

URL http://dx.doi.org/10.1103/PhysRevLett.102. 023001

[33] J. H. Nielsen, P. Simesen, C. Z. Bisgaard, H. Stapelfeldt, F. Filsinger, B. Friedrich, G. Meijer, J. Küpper, Starkselected beam of ground-state OCS molecules characterized by revivals of impulsive alignment, Phys. Chem. Chem. Phys. 13 (2011) 18971-18975. arXiv:1105.2413, doi:10.1039/c1cp21143a.

[34] S. Trippel, J. Wiese, T. Mullins, J. Küpper, Communication: Strong laser alignment of solvent-solute aggregates in the gas-phase, J. Chem. Phys. 148 (10) (2018) 101103. arXiv: 1801.08789 , doi:10.1063/1.5023645.

URL http://aip.scitation.org/doi/10.1063/1. 5023645

[35] L. Holmegaard, J. L. Hansen, L. Kalhøj, S. L. Kragh, H. Stapelfeldt, F. Filsinger, J. Küpper, G. Meijer, D. Dimitrovski, M. Abu-samha, C. P. J. Martiny, L. B. Madsen, Photoelectron angular distributions from strong-field ionization of oriented molecules, Nat. Phys. 6 (2010) 428. arXiv:1003.4634, doi:10.1038/NPHYS1666. URL https://www.nature.com/articles/nphys 1666

[36] C. I. Blaga, J. Xu, A. D. DiChiara, E. Sistrunk, K. Zhang, P. Agostini, T. A. Miller, L. F. DiMauro, C. D. Lin, Imaging ultrafast molecular dynamics with laser-induced electron diffraction, Nature 483 (7388) (2012) 194-197. doi:10.1038/nature10820.

URL https://www. nature.com/articles/nature10820

[37] J. Yang, M. Guehr, X. Shen, R. Li, T. Vecchione, R. Coffee, J. Corbett, A. Fry, N. Hartmann, C. Hast, K. Hegazy, K. Jobe, I. Makasyuk, J. Robinson, M. S. Robinson, S. Vetter, S. Weathersby, C. Yoneda, X. Wang, M. Centurion, Diffractive imaging of coherent nuclear motion in isolated molecules, Phys. Rev. Lett. 117 (2016) 153002. doi:10.1103/PhysRevLett.117.153002. URL https://link.aps.org/doi/10.1103/ PhysRevLett.117.153002

[38] A. Trabattoni, S. Trippel, U. D. Giovannini, J. F. Olivieri, J. Wiese, T. Mullins, J. Onvlee, S.-K. Son, A. R. Biagio Frusteri, J. Küpper, Setting the clock of photoelectron emission through molecular alignmentarXiv: 1802.06622 .

URL https://arxiv.org/abs/1802.06622 


\title{
Supplementary information: Spatial separation of pyrrole and pyrrole-water clusters
}

\author{
Melby Johny ${ }^{\mathrm{a}, \mathrm{c}}$, Jolijn Onvlee ${ }^{\mathrm{a}}$, Thomas Kierspel ${ }^{\mathrm{a}, \mathrm{c}, \mathrm{b}, 1}$, Helen Bieker $^{\mathrm{a}, \mathrm{c}, \mathrm{b}}$, Sebastian Trippel ${ }^{\mathrm{a}, \mathrm{b}, *}$, \\ Jochen Küpper ${ }^{\mathrm{a}, \mathrm{c}, \mathrm{b}}$
${ }^{a}$ Center for Free-Electron Laser Science, Deutsches Elektronen-Synchrotron DESY, Notkestrasse 85, 22607 Hamburg, Germany
${ }^{b}$ The Hamburg Center for Ultrafast Imaging, Universität Hamburg, Luruper Chaussee 149, 22761 Hamburg, Germany \\ ${ }^{c}$ Department of Physics, Universität Hamburg, Luruper Chaussee 149, 22761 Hamburg, Germany
}

The mass spectrum of the molecular beam after strong field ionization, recorded in the center of the undeflected $(0 \mathrm{kV})$ molecular beam profile, is shown in Figure 1. In the spectrum, mass peaks that correspond to pyrrole ${ }^{+}$, pyrrole $\left(\mathrm{H}_{2} \mathrm{O}\right)^{+}$, pyrrole $\left(\mathrm{H}_{2} \mathrm{O}\right)_{2}^{+}$, (pyrrole $)_{2}^{+}$, (pyrrole $)_{2}\left(\mathrm{H}_{2} \mathrm{O}\right)^{+}, \quad$ (pyrrole $)_{2}\left(\mathrm{H}_{2} \mathrm{O}\right)_{2}^{+}$, pyrrole $\left(\mathrm{H}_{2} \mathrm{O}\right)_{3}^{+}$, and larger clusters were observed. Column-densities were obtained by integrating the mass spectrum within gates $\pm 0.5 \mathrm{u} / \mathrm{e}$ around the nominal masses of pyrrole ${ }^{+}$, pyrrole $\left(\mathrm{H}_{2} \mathrm{O}\right)^{+}$, (pyrrole $)_{2}^{+}$, and pyrrole $\left(\mathrm{H}_{2} \mathrm{O}\right)_{2}^{+}$; the resulting vertical beam profiles are shown in Figure 2 a. The plotted profiles are for undeflected pyrrole ${ }^{+}(0 \mathrm{kV})$

\footnotetext{
* Corresponding author

Email address: sebastian.trippel@cfel.de (Sebastian Trippel)

$$
U R L:
$$

https://www . controlled-molecule-imaging.org/ (Sebastian Trippel)

${ }^{1}$ Current address: Department of Chemistry, University
} of Basel, Klingelbergstrasse 80, Basel 4056, Switzerland

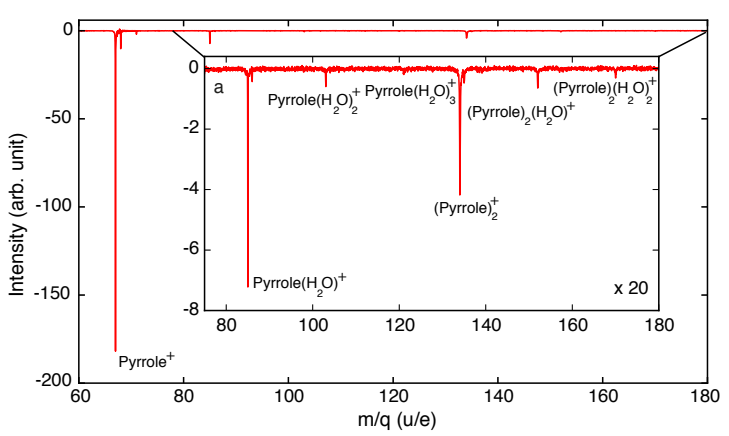

Figure 1: The mass spectra of pyrrole monomer, and larger clusters of pyrrole and water. a) Zoom in of the mass spectrum for clusters.

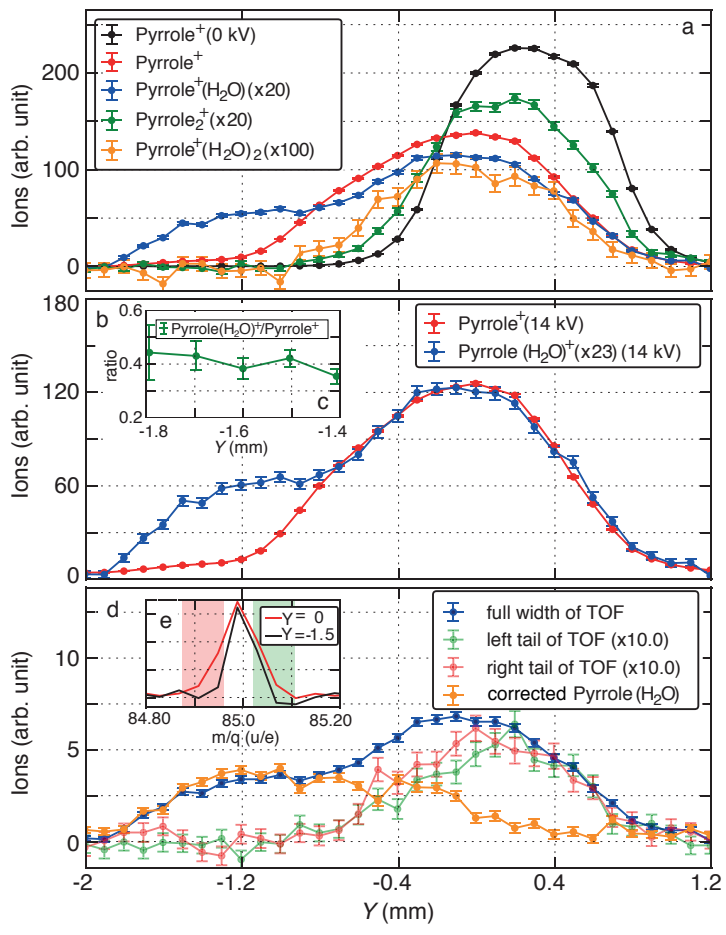

Figure 2: a) Vertical column density profiles recorded for various ion channels. b) Vertical column density profiles of deflected $(14 \mathrm{kV})$ pyrrole ${ }^{+}$and pyrrole $\left(\mathrm{H}_{2} \mathrm{O}\right)^{+}$. c) Ratio of pyrrole $\left(\mathrm{H}_{2} \mathrm{O}\right)^{+} /$pyrrole $^{+}$at positions $-1.8 \mathrm{~mm}<Y<$ $-1.4 \mathrm{~mm}$. d) Molecular beam profile of pyrrole $\left(\mathrm{H}_{2} \mathrm{O}\right)$ with gates covering the full-width of the TOF-MS peak (blue, $m / q=85 \pm 0.5 \mathrm{u} / \mathrm{e}$ ) and curves corresponding to the vertical profile of pyrrole $\left(\mathrm{H}_{2} \mathrm{O}\right)$ with gates set to the wings of TOF-MS peak (red and green), i. e., the red $(m / q=84.88-84.96 \mathrm{u} / \mathrm{e})$ and green $(m / q=85.02-85.10 \mathrm{u} / \mathrm{e})$ shaded regions shown in the inset, e). The orange curve corresponds to the fragmentation corrected column density profile of pyrrole $\left(\mathrm{H}_{2} \mathrm{O}\right)$. e) TOF-MS of deflected $(14 \mathrm{kV})$ pyrrole $\left(\mathrm{H}_{2} \mathrm{O}\right)^{+}$at vertical position $Y=0$ (red) and of pure pyrrole $\left(\mathrm{H}_{2} \mathrm{O}\right)$ beam at $Y=-1.5 \mathrm{~mm}$ (black, $m / q=85 \pm 0.5 \mathrm{u} / \mathrm{e})$. 
and deflected $(14 \mathrm{kV})$ molecular-beam species without any fragmentation correction. The profiles of all species were scaled to the undeflected profile of pyrrole $^{+}$for an improved visibility, see the legend of Figure 2 a for the scaling factors used in the plot. The amount of deflection was in the following order: pyrrole $\left(\mathrm{H}_{2} \mathrm{O}\right)>$ pyrrole $>$ pyrrole $\left(\mathrm{H}_{2} \mathrm{O}\right)_{2}>$ (pyrrole $)_{2}$. Water is expected to deflect less than (pyrrole) $)_{2}$ because of its small effective dipole moment at the electric field strengths used in the experiment. The fragmentation of pyrrole $\left(\mathrm{H}_{2} \mathrm{O}\right)^{+}$ into the pyrrole ion is evident from the matching shape of the deflection profile of the pyrrole ion with that of the pyrrole $\left(\mathrm{H}_{2} \mathrm{O}\right)$ ion at vertical positions $-1.8 \mathrm{~mm}<Y<-1.4 \mathrm{~mm}$. This manifests itself in a constant ratio $R=S$ (pyrrole $\left.\left(\mathrm{H}_{2} \mathrm{O}\right)^{+}\right) / S\left(\right.$ pyrrole $\left.^{+}\right)$ of the specific integrated signals $S(j)$ of the species $j$ in that region as shown in Figure $2 \mathrm{c}$. We have corrected for the contribution of the fragmentation of pyrrole $\left(\mathrm{H}_{2} \mathrm{O}\right)^{+}$into the pyrrole ${ }^{+}$channel using the mean value of the ratio $R$ between vertical positions $-1.8 \mathrm{~mm}<Y<-1.4 \mathrm{~mm}$, $R=S\left(\right.$ pyrrole $\left.\left(\mathrm{H}_{2} \mathrm{O}\right)^{+}\right) / S\left(\right.$ pyrrole $\left.^{+}\right)=0.38$.

The deflection profile of pyrrole $\left(\mathrm{H}_{2} \mathrm{O}\right)$ was also corrected for the fragmentation from larger clusters. For this the width of the TOF-MS peak of pure pyrrole $\left(\mathrm{H}_{2} \mathrm{O}\right)^{+}$in the most deflected part of the beam $(Y=-1.5 \mathrm{~mm})$ was compared with the width of the pyrrole $\left(\mathrm{H}_{2} \mathrm{O}\right)^{+}$peak in the center $(Y=0 \mathrm{~mm})$ of the molecular beam profile where we have contribution from higher clusters, Figure 2 e. The TOFMS of pyrrole $\left(\mathrm{H}_{2} \mathrm{O}\right)^{+}$with contribution from larger clusters (red curve) was broader than the one of the deflected pure pyrrole $\left(\mathrm{H}_{2} \mathrm{O}\right)^{+}$beam (black curve). This is attributed to the kinetic-energy release upon cluster fragmentation; analyzing this allowed us to correct for these contributions. The vertical column density profiles in Figure 2 d obtained by setting gates to the wings of the TOF-MS peak (green line, $m / q=85.02-85.10 \mathrm{u} / \mathrm{e}$ and red line, $m / q=84.88$ $84.96 \mathrm{u} / \mathrm{e})$ were scaled to the least deflected part of the pyrrole $\left(\mathrm{H}_{2} \mathrm{O}\right)^{+}$signal $(m / q=85 \pm 0.5 \mathrm{u} / \mathrm{e})$ at $0.2 \mathrm{~mm}<Y<1 \mathrm{~mm}$, with a scaling factor of 10. The fragmentation corrected pyrrole $\left(\mathrm{H}_{2} \mathrm{O}\right)^{+}$ profile (orange line) was obtained by subtracting these larger-cluster-fragment corrections (green and red lines) from the profile obtained by setting gates to the full width of the TOF-MS peak (blue line, $m / q=85 \pm 0.5 \mathrm{u} / \mathrm{e})$. The kink at vertical positions ranging from $Y=-0.3$ to $-0.8 \mathrm{~mm}$ (blue line) and the shape of the profiles for larger clusters (red and green lines) matched the shape of the deflected

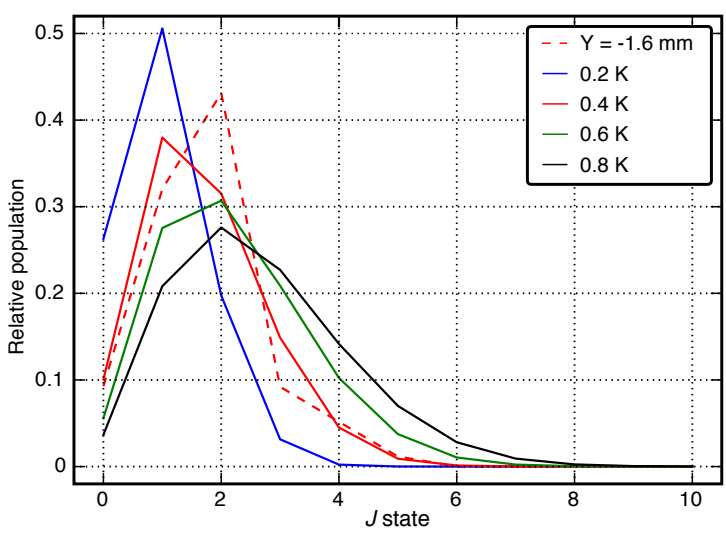

Figure 3: The relative population of the rotational states in the molecular beam at $Y=-1.6 \mathrm{~mm}$ (dashed line) and the thermal distributions at various temperatures (solid lines).

pyrrole $\left(\mathrm{H}_{2} \mathrm{O}\right)_{2}^{+}$in Figure 2 a. Hence, the uncorrected pyrrole $\left(\mathrm{H}_{2} \mathrm{O}\right)^{+}$profile had significant contributions from fragments of larger, weakly deflected, pyrrole $\left(\mathrm{H}_{2} \mathrm{O}\right)_{2}^{+}$cluster into the pyrrole $\left(\mathrm{H}_{2} \mathrm{O}\right)^{+}$and the $\mathrm{H}_{2} \mathrm{O}^{+}$channels.

The purity $P_{i}$ of a species $i$ is defined by $P_{i}=$ $S\left(i^{+}\right) / \sum_{j} S\left(j^{+}\right)$. For our evaluation of the purity, integrated signals from pyrrole ${ }^{+}$, pyrrole $\left(\mathrm{H}_{2} \mathrm{O}\right)^{+}$, pyrrole $\left(\mathrm{H}_{2} \mathrm{O}\right)_{2}^{+}$, (pyrrole $)_{2}^{+}$, (pyrrole $)_{2}\left(\mathrm{H}_{2} \mathrm{O}\right)^{+}$, and (pyrrole $)_{2}\left(\mathrm{H}_{2} \mathrm{O}\right)_{2}^{+}$were taken into account; larger clusters were neglected.

The relative populations of rotational states of pyrrole $\left(\mathrm{H}_{2} \mathrm{O}\right)$ in the molecular beam at $Y=$ $-1.6 \mathrm{~mm}$ was determined from the simulations, see Figure 3; this distribution is non-thermal due to the nature of the deflection process. The rotational state distribution for a range of temperatures are also shown in the plot. The relative populations in the deflected part of the beam matches fairly well with a thermal distribution of $T_{\text {rot }} \approx 0.4 \mathrm{~K}$. This confirms that ultracold molecular beams, even of isolated well-defined molecular clusters, can be generated in the most deflected part of a dispersed molecular beam. 